\section{Kidney \\ Blood Pressure Research}

Kidney Blood Press Res 2013;38:109-120

Review

\title{
Aging and Chronic Kidney Disease
}

\author{
Kosaku Nittaa,b Kazuyoshi Okadaa,c Mitsuru Yanai ${ }^{\mathrm{a}, \mathrm{c}}$ Susumu Takahashia \\ aInternational Kidney Evaluation Association Japan (IKEAJ); ${ }^{b}$ Department of Medicine, Kidney Center, \\ Tokyo Women's Medical University; 'Department of Medicine, Nihon University School of Medicine, \\ Tokyo, Japan
}

\section{Key Words}

Aging $\bullet$ Chronic kidney disease $・$ Elderly $\bullet$ ESRD $・$ Nephrology care $・$ Survival

\begin{abstract}
A recent report has dealt with geriatric nephrology, including epidemiology and pathophysiology of chronic kidney disease (CKD), attempting to get nephrologists to pay more attention to elderly CKD patients. The aims of this article are to summarize the morphological and functional properties of the aging kidney, and to better understand nephrology care for elderly CKD patients. The kidneys are affected by the aging process, which results in numerous effects on the renal system. In addition, the elderly population is hetereogenous - some have a decline in GFR explained by diseases that complicate aging such as arteriosclerosis with hypertension, whereas in the most of healthy adults the decline in GFR is much more modest and not inevitable. The values for normal estimated glomerular filtration rate (eGFR) in aging population have important implications for the diagnosis of CKD in the elderly. However, the MDRD equation underestimates mean eGFR by $25 \%$ and the CKD-EPI equation underestimates mean GFR by $16 \%$. This bias may lead to misclassifying healthy older persons as having CKD. It is also still unknown whether and how age influences the predictive role of other risk factors for end-stage renal disease (ESRD) and death in referred as well as unreferred patients. The risk of ESRD was reported to be higher than the risk of death without ESRD for ages $<60$ years, and independent of eGFR. Proteinuria significantly increased the risk of ESRD with advancing age. In older patients on nephrology care, the risk of ESRD prevailed over mortality even when eGFR was not severely impaired. Proteinuria increases the risk of ESRD, while the predictive role of other modifiable risk factors was unchanged compared with younger patients. The decision to initiate renal replacement therapy in the elderly is complicated by more challenges than in younger patients. Calorie restriction and Klotho deficiency may be a candidate therapeutic target for attenuating kidney aging.
\end{abstract}




\section{Kidney \\ Blood Pressure Research}

\section{Introduction}

The prevalence of non-dialysis chronic kidney disease (CKD), defined as an estimated glomerular filtration rate (eGFR) $<60 \mathrm{ml} / \mathrm{min}$ per $1.73 \mathrm{~m}^{2}$, is markedly higher in elderly populations [1, 2]. In Japan, the elderly population; i.e., those aged 65 and over, accounted for $25.8 \%$ of the total population in October 2010, and this will increase to $30.5 \%$ by 2025 [3], predicting a further increase in prevalence is occurring among those aged 65 years and older. Across three databases, the Kidney Early Evaluation Program, National Health, Nutrition Examination Survey, and Medicare, the prevalence of CKD in the elderly population (aged> 65 years) was approximately 44\%, with the highest representation observed in those aged 80 years and older $[4,5]$. It is also estimated that the number of elderly patients with treated end-stage renal disease (ESRD) has almost doubled in the past 25 years [6, 7]. A recent report has dealt with geriatric nephrology, including epidemiology and pathophysiology of CKD [8], attempting to get nephrologists to pay more attention to elderly CKD patients.

CKD is diagnosed in healthy elderly subjects whose renal function is below the normal range $\left(60 \mathrm{ml} / \mathrm{min}\right.$ per $\left.1.73 \mathrm{~m}^{2}\right)$. However, it is difficult to know the anatomy of the kidney change with natural aging in the absence of CKD. It is important to emphasize that even though the aged kidney has a decreased GFR, it differs in many ways from that in patients who are commonly affected with many causes of kidney diseases (Table 1). Healthy, very old persons older than 85 years and patients with stage 3 CKD share two main physiological characteristics: a similarly low GFR about $50 \mathrm{ml} / \mathrm{min}$ per $1.73 \mathrm{~m}^{2}$, and a diminished ability for salt and water reabsorption from the renal tubule. However, despite these similarities, the aged kidney and chronically damaged one differ markedly in a number of physiological aspects as previously described [9]. With living kidney donation there is a need to clarify what is normal for the age of the kidneys. Alive kidney donors provide a unique opportunity to study the impact of loss of renal parenchyma compared to normal aging. The aims of this article are to summarize the morphological and functional properties of the aging kidney, and to better understand nephrology care for elderly CKD patients.

Table 1. Diseases commonly affected the aging kidney

\begin{tabular}{ll}
\hline Diseases commonly affected the aging kidney \\
\hline Systemic diseases & Diabetes mellitus \\
& Dyslipidemia \\
& Atherosclerosis \\
& Myeloma cast nephropathy \\
& Amyloidosis \\
& Light-chain deposition disease \\
& Vasculitides \\
& Membranous nephropathy \\
Glomerular diseases & Mesangial proliferative GN \\
& ANCA-associated GN \\
& Minimal change disease \\
& Focal segmental glomerulosclerosis \\
Interstitial nephritis & - \\
Other causes of kidney diseases & Inflammatory renal diseases \\
& Drug-induced nephropathy \\
Urinary tract infection & - \\
Obstructive uropathy & Neurogenic bladder \\
& Renal stones \\
& Obstructive pyelonephritis/papillary necrosis \\
& Cancers of prostate and bladder \\
\hline ANCA, ani-neutrophil cytoplasmic antibody; GN, glomerulonephritis \\
\hline
\end{tabular}




\section{Kidney Blood Pressure Research}

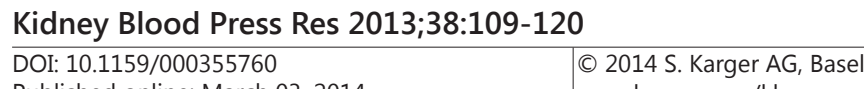

Publisned onIIne: vararch 03, 2014 www.karger.com/kbr

Nitta/Okada/Yanai/Takahashi: Aging and CKD

\section{Morphological changes of the aging kidney}

The kidneys are affected by the aging process, which results in numerous effects on the renal system [10]. Renal mass decreases between the ages of 30 and 80 years, with the steepest decline observed after age 50 [11]. Fat and fibrosis scarring, which may replace some parenchymal tissue, occurs primarily in the renal cortex (Figure 1) and scarring affects the nephrons that are important for maximal urine concentration. Even in normal aging kidneys, $30 \%$ of the glomeruli are destroyed and display diffuse glomerular sclerosis by age 75 [12], and the remaining glomeruli exhibit impaired filtering ability. The results from aging studies in animals and humans suggest that diverse factors contribute to the scarring process, such as tissue ischemia, injury, hypertension, metabolic defects and obesity.

The age-related findings on light microscopic evaluation of kidney biopsies can be divided into two groups: (1) nephrosclerosis including glomerulosclerosis, tubular atrophy, interstitial fibrosis, and arteriosclerosis) and (2) morphometric analysis of microanatomy such as measuring glomerular size. Previous studies had shown an increased proportion of globally sclerotic glomeruli with aging [13-15]. The glomerulosclerosis that occurs with aging has an ischemic appearance with tuft collapse and intracapsular fibrosis, suggesting a primary vascular origin for the lesions. Some functional glomeruli show ischemic capillary wrinkling of tufts, thickening of basement membranes, and mild intracapillary fibrosis, all of which are precursors for glomerulosclerosis. Over time, shrinkage of the glomerular tufts with sclerosis and collagen deposition filling Bowman's space develops [16]. Besides glomerulosclerosis, increased arteriosclerosis, medial hypertrophy, and arteriolar hyalinosis occur with aging [15]. As a result of the sclerosis of juxtaglomerular glomeruli, formation of a direct connection is established between afferent and efferent arterioles that bypasses the tuft [17]. Tubular atrophy with surrounding areas of interstitial fibrosis increases with aging.

\section{Functional changes in renal function with aging}

In the Baltimore studies Lindeman et al. [18] reported the results of the longitudinal studies concerning the rate of decline in renal function with age. In a total of 254 presumably normal men were studied with serial creatinine clearance (Ccr) was studied over a 5- to 14-year period. The average decline of Ccr was $0.75 \mathrm{ml} / \mathrm{min} /$ year. As many as $1 / 3$ of the subjects showed a stable Ccr over time. This study has been widely cited to challenge the concept that the decline in renal function with age is inexorable.

Many years later, the controversy regarding the inevitability of the decline in renal function with aging was evaluated by Fliser et al. $[19,20]$. These authors suggested that the elderly population was hetereogenous - some have a decline in GFR explained by diseases that complicate aging such as arteriosclerosis with hypertension, whereas in most of healthy adults the decline in GFR is much more modest and not inevitable. Fliser et al. also proposed that the renal functional changes accompanying aging might be the consequence of an 


\section{Kidney Blood Pressure Research}

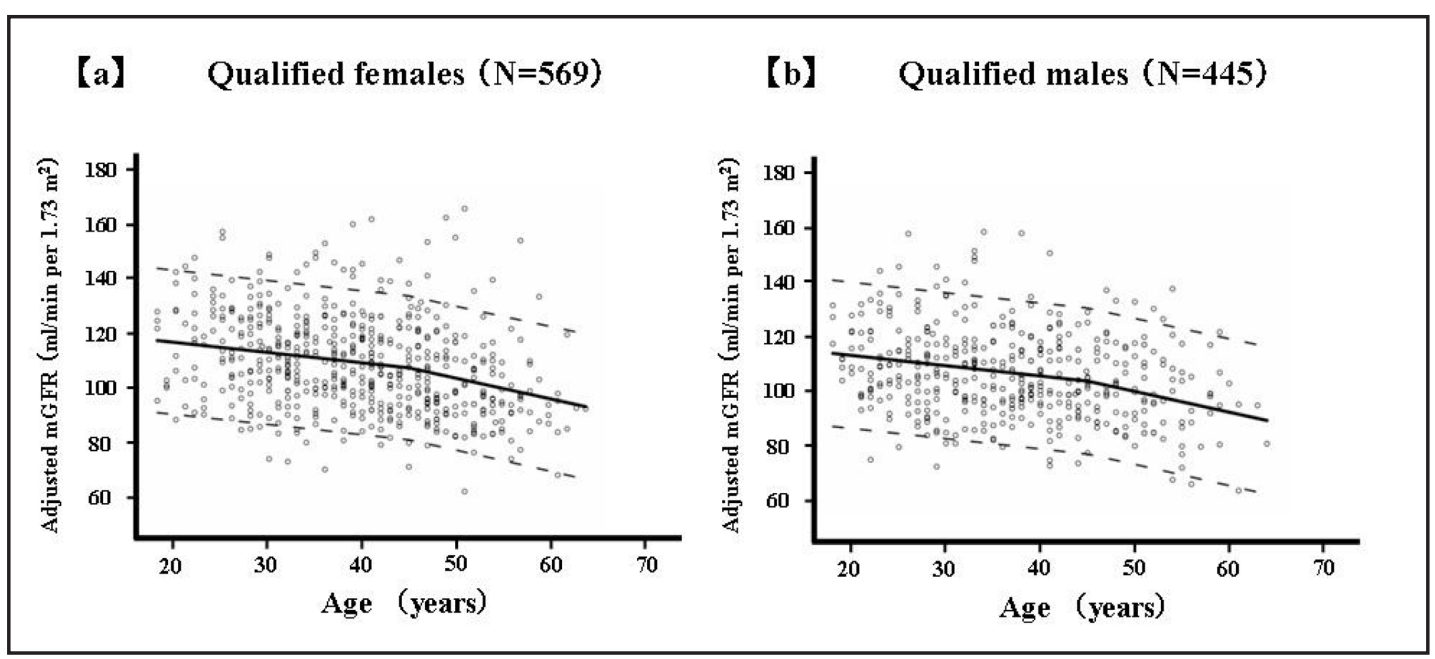

Fig. 2. Effects of age on renal function. Influence of donor age on the slope of glomerular filtration rate in (a) women and (b) men Cited from reference [25].

altered responsiveness to vasodilators and vasoconstrictors [21]. This thesis is based on observations that the filtration fraction increases with aging, due to a disproportionate fall in renal plasma flow relative to GFR. The filtration fraction apparently doses not begin to increase until after the age of 60 or 70 years, yet the decline in GFR begins at age 30-40 years.

Hollenberg et al. [22, 23] reported an interesting study from an island-dwelling indigenous population which is remarkably free of the cardiovascular (CV) disease commonly affecting the elderly in non-island Panamanians. This cohort failed to show show any progressive increase in blood pressure with age. Both GFR and renal plasma flow decline with age in the Kuna Indians - the slope of renal plasma flow and GFR relative to age was greater in the Kuna Indians compared with age-matched residents of Boston. This is one of the few studies that potentially disassociate the diseases of aging that are often attributed to a modern lifestyle from the renal function changes accompanying normal senescence. Moreover, several investigations have been reported on potential changes of renal function in living kidney donors of kidney allografts [24, 25]. Since kidney donors are rigorously evaluated to ensure no abnormalities before donation. In these individuals a progressive decline in GFR with age even after excluding donors with CKD or CKD risk factors.

Creatinine is the endogenous marker that has been widely used for estimation of renal function. The Cockcroft-Gault formula [26], which estimates Ccr without adjusting body surface area, and the modification of diet in renal disease (MDRD) formula, which estimates GFR adjusted to standard body surface area of $1.73 \mathrm{~m}^{2}$ [27] are the most studied serum creatinine-based equations. A newer modification of the eGFR known as the CKD-EPI equation [28] uses the same variables as the MDRD equation but was developed using a more diverse sample of patients. The Japanese Society of Nephrology proposed the creatininebased equations for Japanese [29]. The inclusion of age and gender as variables is to provide surrogacy for anticipated endogenous creatinine production rate, which inevitably declines with age due to loss of lean body mass [30]. Figure 2 shows a representative study of eGFR using MDRD equation in normal kidney donor [25], indicating that the mean value for eGFR is about $105 \mathrm{ml} / \mathrm{min}$ per $1.73 \mathrm{~m}^{2}$ for 18 - to 24 -year-old men and $102 \mathrm{ml} / \mathrm{min}$ per $1.73 \mathrm{~m}^{2}$ for 18- to 24-year-old women. The mean eGFR declines to about $80 \mathrm{ml} / \mathrm{min}$ per $1.73 \mathrm{~m}^{2}$ and 78 $\mathrm{ml} / \mathrm{min}$ per $1.73 \mathrm{~m}^{2}$ in 65 -year-old men and women, respectively.

These values for normal eGFR in aging population have important implications for the diagnosis of CKD in the elderly [31,32]. Since the NKF-KDOQI proposed the classification and staging schema for CKD [33], CKD has since been diagnosed on the basis of an isolated 


\section{Kidney Blood Pressure Research}

eGFR value $<60 \mathrm{ml} / \mathrm{min}$ per $1.73 \mathrm{~m}^{2}$. In the eGFR $45-59 \mathrm{ml} / \mathrm{min}$ per $1.73 \mathrm{~m}^{2}$ range for healthy adults, the MDRD equation underestimates mean eGFR by $25 \%$ and the CKD-EPI equation underestimates mean GFR by $16 \%$ [34]. This bias may lead to misclassifying healthy older persons as having CKD. With current criteria, the great majority of subjects diagnosed as having CKD stage 3 are over 65 years of age [35].

\section{The risk of ESRD in the elderly with CKD}

Elderly patients have become prevalent also in nephrology clinics [36-38]. This epidemiological finding is critical for three reasons. First, nephrologists represent the main reference of care for patients with overt non-dialysis CKD. Second, the number of elderly patients referred to a nephrologist has significantly grown in the past decade [39]. Third, worldwide patients followed in the nephrology setting are characterized by more advanced renal disease and higher burdens of CVD comorbidities as compared with unreferred patients [40-44].

In spite of the changing epidemiology of non-dialysis CKD in nephrology clinics, no prognostic information has thus far been provided on the elderly patients under nephrology care. This gap of knowledge is particularly important because many elderly patients, unreferred or newly referred to nephrology clinics, do not follow an inexorable course to ESRD because they commonly die before reaching ESRD [45-47]. It is also still unknown whether and how age influences the predictive role of other risk factors for ESRD and death in referred as well as unreferred patients. Nicola et al. [48] have recently reported the modifying effect of age on the competing risk of ESRD vs. death and on the predictive role of the main risk factors in a cohort of patients with non-dialysis CKD under stable nephrology care. In their cohort, the rate of combined end point of ESRD and death without ESRD more than doubled in patients over 75 as compared with younger patients, and this risk excess went along with a steep increase of death. Age modified the risks of the two competing end points depending on the eGFR level.

Indeed, while the risk for ESRD surpassed death risk independently from eGFR up to 60 years of age, the risk of death without ESRD tended to prevail in older age strata. However, ESRD still represented the more frequent outcome not only in elderly patients with stage 5 CKD, but also in those with less severe kidney disease, as it was the case in patients in the $65-75$ years stratum with eGFR in the $20-35 \mathrm{ml} / \mathrm{min}$ per $1.73 \mathrm{~m}^{2}$ range [48]. These findings complement the analysis by O'Hare et al who compared the crude incidence rates of ESRD and death in a large cohort of US Veterans with CKD stages 3-5 CKD [46]. In that cohort, the incidence of death was fivefold greater than that of ESRD, and the eGFR thresholds marking a greater ESRD risk vs. mortality were much lower than the cohort reported by Nicola et al [48]. In particular, in middle-aged patients (45-65 years) rates of ESRD surpassed mortality only if eGFR was $<30 \mathrm{ml} / \mathrm{min}$ per $1.73 \mathrm{~m}^{2}$, and the same occurred for patients aged $65-75$ years exclusively when eGFR was $<15 \mathrm{ml} / \mathrm{min}$ per $1.73 \mathrm{~m}^{2}$.

The effect of age on the fate of CKD patients does not represent the only critical issue in contemporary geriatric nephrology research, and in clinical practice as well; attention in fact has been recently drawn to the gaps of knowledge on age-related differences in the mechanisms and pathways that contribute to progression to ESRD and mortality [2]. This information is essential to better delineate the risk profile, and preliminary to the identification of therapeutic goals, in elderly patients. Nicola et al [48] found that in the early stages of CKD, the presence of higher proteinuria significantly increased the risk of ESRD in older patients, suggesting that the kidney of elderly patients is more vulnerable to the 'nephrotoxic' effects of proteinuria due to the greater degree of renal fibrosis and ischemia [49]. To our knowledge, only one study has evaluated the impact of overt proteinuria by according to age on ESRD in tertiary nephrology care [38]. They found that overt proteinuria 


\section{Kidney Blood Pressure Research}

is associated with ESRD in elderly patients; but their analysis is limited by the low number of risk factors included in the Cox analysis, the inconsistent definition of overt proteinuria, and, more importantly, by the retrospective design and the small sample size.

\section{CVD in elderly CKD patients}

While the CKD epidemic grew, evidence emerged that even mild degrees of renal dysfunction are associated with increased risk of cardiovascular morbidity and mortality [50]. This association has led to the suggestion of a causal relation between CKD and cardiovascular disease, and consequently the CKD epidemic has been recognized as a major public health issue that may substantially challenge global healthcare resources [51].

To date, the type of relationship between CKD and CVD is unclear, and this poses two key questions. First, is age a confounding factor that links CKD to CVD via either (i) over-inflating the recognition of CKD, as discussed previously, or (ii) by representing an independent CVD risk factor? It is obvious to note that age is one of the most powerful predictors for all-cause mortality and for CVD mortality in particular. Second, is the relationship between CKD and CVD a primary (i.e. renal disease is a causal factor of CVD) or secondary association (i.e. both act as different manifestations of a common determinant)? Thus, it is tempting to speculate that there may be an association between demographics and CVD outcomes in patients with CKD. Patients with less severe degrees of renal impairment seem to be at increased risk of CVD, and they may represent an ideal target for secondary and tertiary preventive initiatives. As CKD and CVD are more frequent in the elderly, the possibility that an age-related process could be the unifying factor that associates CKD and CVD should be investigated.

An analysis conducted on more than 2500000 US veterans showed that a mildto-moderate reduction in eGFR was not associated with an increase in CVD mortality in individuals over 65 years of age [52]. The same results have been recently confirmed in a community based elderly population ( $\geq 75$ years of age): both men and women with an eGFR between 45 and $59 \mathrm{ml} / \mathrm{min}$ per $1.73 \mathrm{~m}^{2}$ showed no differences in all-cause and cardiovascular mortality when compared to individuals with an eGFR $>60 \mathrm{ml} / \mathrm{min}$ per $1.73 \mathrm{~m}^{2}$ [53]. These findings suggest that individuals with eGFR values of $45-59 \mathrm{ml} / \mathrm{min}$ per $1.73 \mathrm{~m}^{2}$ mainly include those with age-related kidney dysfunction rather than with 'real' CKD predisposing to CVD.

\section{Renal replacement therapy (RRT) in the elderly population}

The decision to initiate RRT in the elderly is complicated by more challenges than in younger patients. Beyond geriatric syndromes, elderly patients more likely face problems with nonmedical barriers, including limited transportation, family support, and income, furthermore, the elderly also have more frequently cardiovascular and overall comorbid conditions as well as reduced life expectancy compared with younger patients $[54,55]$.

Timing of dialysis initiation must be considered. The IDEAL (Initiating Dialysis Early and Late) study found no benefit for early initiation [56], and another study suggested that in the elderly it may even be associated with harm, perhaps because of accelerated loss of residual renal function [57]. Therefore, it becomes important to provide patients and families with prognostic information regarding timing of initiation, further complicated by assessing the competing mortality risk (likelihood of death in some elderly before ESRD is reached) [58].

A recent clinical practice guideline aims to provide aid in the decision when to initiate dialysis [59]. Shared decision-making, wherein patient values and preferences are strongly considered, is emphasized [59]. Advanced care planning is improved by

identifying the patient's preferences and by using specific documents (i.e., Physician Orders for Life-Sustaining Treatment) [59]. The guideline emphasizes communication skills 


\section{Kidney Blood Pressure Research}

\begin{tabular}{l|l}
\hline Kidney Blood Press Res 2013;38:109-120 \\
\hline DOI: $10.1159 / 000355760$ & (C) 2014 S. Karger AG, Basel
\end{tabular}

Publisned onIIne: IVIarch 03, 2014 www.karger.com/kbr

Nitta/Okada/Yanai/Takahashi: Aging and CKD

for breaking bad news and conflict resolution [59]. Time-limited dialysis trials are useful in cases with uncertain prognosis or no consensus [58-60].

Some patients with ESRD do not wish RRT. A non-dialytic strategy known in Europe as maximum conservative management (MCM) may be used [61-64]. For this intensive approach to CKD a multidisciplinary clinical program is provided staffed by dietitians, social workers, and other support personnel. Patients receive the same care as they do in earlier CKD stages, with an emphasis on supportive, symptomatic care.

Murtagh et al. analyzed retrospectively in a MCM clinic elderly patients above age 75 years [65]. After study criteria were applied, 129 patients were analyzed: 52 who chose dialysis and 77 who chose MCM. None receiving MCM switched to dialysis. Dialysis withdrawal rates and hospice use were not discussed. Dialysis patients achieved a 2-year survival rate of $76 \%$ compared with $47 \%$ for those receiving MCM. Such mortality benefit was not observed, however, for patients with CVD or high comorbidity.

Despite such potential survival benefit, dialysis may not improve quality of life; among dialysis patients $65 \%$ of deaths occurred while they were hospitalized, compared with $27 \%$ for those receiving MCM [66]. Carson et al. also reported that dialysis patients lived longer than MCM patients (median survival duration, 37.8 months versus 13.9 months, respectively), but spent more time in or at the hospital (173 days per patient-year versus 16) [67]. Those receiving MCM were four-fold more likely to die at home or in a hospice.

\section{Future directions and perspectives}

Numerous metabolic, physiological and pathological factors contribute to the pathogenesis of kidney aging. Repeated tissue inflammation is one of the factors involved in the kidney aging process and underlying disease conditions are important therapeutic targets for the prevention of kidney aging [68]. In addition to these established risk factors and interventions targeting them, e.g., renin-angiotensin system blockade, Kanasaki et al. reviewed in addition, molecules associated with kidney aging as well as potential methods for combating kidney aging [69].

Calorie restriction consists of established dietary interventions that have been shown to increase both the median and maximum lifespan of a variety of species [70]. The health benefits of calorie restriction have also been demonstrated in primates; calorie restriction in rhesus monkeys blunts aging and significantly delays the onset of age-related disorders, including cancer, diabetes, and CVD [71]. Numerous molecules may mediate the beneficial effects of calorie restriction. Among these calorie restriction-mediated molecules, sirtuin 1 (SIRT1) has a well-established importance in calorie restriction-mediated signaling [72]. Calorie restriction likely enhances SIRT1 activity in most tissues, including the kidneys $[73,74]$. In support of this finding, in SIRT1 knockout mice, the beneficial effects of calorie restriction are diminished [74]. SIRT1 transgenic mice display a similar phenotype in response to calorie restriction [75]. The potential SIRT1 activator, resveratrol, may induce a similar transcriptional profile to that of calorie restriction and provide protection against glomerulosclerosis [76-78].The significance of resveratrol dependence on SIRT1 activation in renoprotection is, however, controversial [79]. Although the beneficial effects of calorie restriction and SIRT1 activation on halting kidney aging and exptending longevity has not yet been reported in humans, the above evidence indicates that calorie restriction and/or SIRT1 activation may provide a potential clue to combat kidney aging.

The Klotho gene encodes a transmembrane protein and is expressed primarily in the kidney [80] and Kuro-o et al reported that mutations in the Klotho gene in mice resulted in multiple phenotypes of human aging, such as the calcification of soft tissue and vascular walls, hyperphosphatemia, muscle and skin atrophy, and early death. Furthermore, Klotho gene overexpression in mice has been shown to extend life span when compared with control mice [81]. The Klotho gene has vital roles in the regulation of both phosphorus 


\section{Kidney \\ Blood Pressure Research}

and calcium phosphate transport [82]. Membrane-bound Klotho functions as the obligate coreceptor for fibroblast growth factor (FGF) 23, and any defects in the function of either Klotho or FGF23 in mice lead to phosphate accumulation and premature aging [83]. Patients with CKD eventually suffer premature death not from renal failure, but as a result of the early onset of common aging-related diseases, such as CVD and diabetes [84]. CKD patients exhibit remarkable declines in the kidney expression of Klotho [85], which is associated with resistance to FGF23 [86], hyperphosphatemia and vascular calcification - symptoms similar to those of Klotho-deficient mice [80, 81]. These data suggest a significant link between phosphate metabolism and kidney aging. Thus, Klotho deficiency may be a candidate therapeutic target for kidney aging [85].

\section{Conclusion}

In almost every country, the proportion of people over 60 years of age is increasing much faster than any other age group as a result of both longer life expectancy and declining fertility rates. Functional deficiencies in the kidney may be associated with health problems in multiple organs. Therefore, the prevention of kidney aging may be an appropriate approach for combating age-related diseases. Aging kidneys are good candidates for such interventions. There is a possibility that aging process in kidneys is preventable.

\section{Conflict of Interests}

All the authors declared no competing interests.

\section{Acknowledgments}

The authors thank Mr. Nobuo Ito, Ms Miyako Okamoto, Ms. Yumi Suzuki, and Mrs Sachiko Miyaguchi for skillful assistance for preparing this manuscript.

\section{References}

1 Prakash S, O’Hare AM: Interaction of aging and chronic kidney disease. Semin Nephrol 2009;29:497-503.

-2 Anderson S, Halter JB, Hazzard WR Hazzard WR, Himmelfarb J, Horne FM, Kaysen GA, Kusek JW, Nayfield SG, Schmader K, Tian Y, Ashworth JR, Clavton CP, Parker RP, Tarver ED, Woolard NF, High KP; workshop participants: Prediction, progression, and outcomes of chronic kidney disease in older adults. J Am Soc Nephrol 2009;20:1199-1209.

3 White Book of Aging from the Government of Japan: http://www8.cao.go.jp/kourei/whitepaper/w-2011/ gaiyou/pdf/1s1s.pdf (Accessed, April 2, 2012).

4 Stevens LA, Li S, Wang C, Huang C, Becker BN, Bomback AS, Brown WW, Burrows NR, Jurkovitz CT, McFarlane SI, Norris KC, Shilipak M, Whaley-Connell AT, Chen SC, Bakris GL, McCullough PA: Prevalence of CKD and Comorbid Illness in Elderly Patients in the United States: Results from the Kidney Early Evaluation Program (KEEP). Am J Kidney Dis 2010;55:S23-S33.

-5 Takahashi S, Okada K, Yanai M: The Kidney Early Evaluation Program (KEEP) of Japan: Results from the Initial Screening Period. Kidney Int Suppl 2010;116:S17-S23.

6 Gambaro G, Yabarek T, Graziani MS, Gemelli A, Abaterusso C, Frigo AC, Marchionna N, Citron L, Bonfante L, Grigoletto F, Tata S, Ferraro PM, Legnaro A, Meneghel G, Conz P, Rizzotti P, D’Angelo A, Lupo A; INCIPE Study group: Prevalence of CKD in Northeastern Italy: Results of the INCIPE Study and Comparison with NHANES. Clin J Am Soc Nephrol 2010;5:1946-1953. 


\section{Kidney \\ Blood Pressure Research}

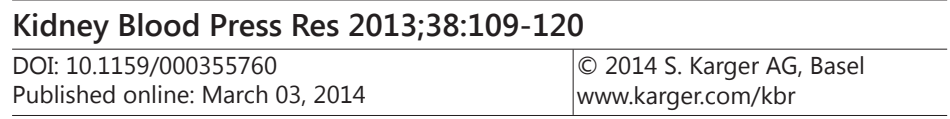

Nitta/Okada/Yanai/Takahashi: Aging and CKD

7 Nakai S, Iseki K, Itami N, Ogata S, Kazama JJ, Kimata N, Shigematsu T, Shinoda T, Shoji T, Suzuki K, Taniguchi M, Tsuchida K, Nakamoto H, Nishi H, Hashimoto S, Hasegawa T, Hanafusa N, Hamano T, Fujii N, Masakane I, Marubayashi S, Morita O, Yamagata K, Wakai K, Wada A, Watanabe Y, Tsubakihara Y: An Overview of Regular Dialysis Treatment in Japan (as of 31 December 2010). Ther Apher Dial. 2012;16:483-521.

8 Musso CG, Orepoulos DG: Aging and physiological changes of the kidneys including changes in glomerular filtration rate. Nephron Physiol 2011;119:1-5.

9 Musso CG, Macias Nunez JF, Oreopoulos DG: Physiological similarities and differences between renal aging and chronic renal disease. J Nephrol 2007;20:586-587.

10 Zhou XJ, Rakheja D, Yu X, Saxena R, Vaziri ND, Silva FG: The aging kidney. Kidney Int 2008;74:710-720.

-11 Epstein M: Aging and the Kidney. J Am Soc Nephrol 1996;7:1106-1122.

-12 Nyengaard JR, Bendtsen TF: Glomerular number and size in relation to age, kidney weight, and body surface in normal man. Anat Rec 1992;232:194-201.

-13 Kubo M, Kiyohara Y, Kato I, Tanizaki Y, Katafuchi R, Hirakata H, Okuda S, Tsuneyoshi M, Sueishi K, Fujishima M, Iida M: Risk factors for renal glomerular and vascular changes in an autopsy-based population survey: the Hisayama Study. Kidney Int 2003;63:1508-1515.

14 Hoy WE, Douglas-Denton RN, Hughson MD, Cass A, Johnson K, Bertram JF: A stereological study of glomerular number and volume: Preliminary findings in a multiracial study of kidneys at autopsy. Kidney Int Suppl 2003;63:S31-S37.

15 Rule AD, Amer H, Cornell LD, Taler SJ, Cosio FG, Kremers WK, Textor SC, Stegall MD: The association between age and nephrosclerosis on renal biopsy among healthy adults. Ann Intern Med 2010;152:561567.

16 Wiggins JE, Goyal M, Sanden SK, Wharram BL, Shedden KA, Misek DE, Kuick RD, Wiggins RC: Podocyte hypertrophy, 'adaptation,' and 'decompensation' associated with glomerular enlargement and glomerulosclerosis in the aging rat: prevention by calorie restriction. J Am Soc Nephrol 2005;16:29532966.

17 Takazakura E, Sawabu N, Handa A, Takada A, Shinoda A, Takeuchi J: Intrarenal vascular changes with age and disease. Kidney Int 1972;2:224-230.

18 Lindeman RD, Tobin J, Shock NW: Longitudinal studies on the rate of decline in renal function with age. J Am Geriatr Soc 1985;33:278-285.

19 Fliser D, Franek E, Ritz E: Renal function in the elderly- is the dogma of an inexorable decline of renal function correct? Nephrol Dial Transplant 1997;12:1553-1555.

20 Fliser D: Ren Sanus in Corpore Sano: the myth of the inevitable decline of renal function with senescence. Nephrol Dial Transplant 2005;20:482-485.

21 Fliser D, Ritz E: Renal hemodynamics in the elderly. Nephrol Dial Transplant 1996;11:S2-S8.

22 Hollenberg NK, Martinez G, McCullough M, Meinking T, Passan D, Preston M, Rivera A, Taplin D, VicariaClement M: Aging, acculturation, salt intake and hypertension in the Kuna of Panama. Hypertension 1997;29:171-176.

23 Hollenberg NK, Rivera A, Meinking A, Martinez G, McCullough M, Passan D, Preston M, Taplin D, VicariaClement M: Age, renal perfusion and function in island dwelling indigenous Kuna Amerinds of Panama. Nephron 1999;82:131-138.

-24 Rule AD, Gussak HM, Pond GR, Bergstralh EJ, Stegall MD, Cosio FG, Larson TS: Measured and estimated GFR in healthy potential kidney donors. Am J Kidney Dis 2004;43:112-119.

-25 Poggio ED, Rule AD, Tanchanco R, Arrigain S, Butler RS, Srinivas T, Stephany BR, Meyer KH, Nurko S, Fatica RA, Shoskes DA, Krishnamurthi V, Goldfarb DA, Gill I, Schreiber MJ Jr: Demographic and clinical characteristics associated with glomerular filtration rates in living kidney donors. Kidney Int 2009;75:1079-1087.

-26 Cockcroft DW, Gault MH: Prediction of creatinine clearance from serum creatinine. Nephron1976;16:31-41.

27 Levey AS, Bosch J, Lewis JB: A More accurate method to estimate glomerular filtration rate from serum creatinine: a new prediction equation. Modification of Diet in Renal Disease Group. Ann Intern Med 1999;130:461-470.

28 Levey AS, Stevens LA, Schmid CH, Zhang YL, Castro AF 3rd, Feldman HI, Kusek JW, Eggers P, Van Lente F, Greene T, Coresh J; CKD-EPI (Chronic Kidney Disease Epidemiology Collaboration): A new equation to estimate glomerular filtration rate. Ann Intern Med 2009;150:604-612. 


\section{Kidney \\ Blood Pressure Research}

29 Matsuo S, Imai E, Horio M, Yasuda Y, Tomita K, Nitta K, Yamagata K, Tomino Y, Yokoyama H, Hoshida A; Collaborators developing the Japanese equation for estimated GFR: Revised equations for estimated GFR from serum creatinine in Japan. Am J Kidney Dis 2009;53:982-992.

-30 Epstein M: Aging and the kidney. J Am Soc Nephrol 1996;7:1106-1122.

31 Winearls CG, Glassock RJ: Dissecting and refining the staging of chronic kidney disease. Kidney Int 2009;75:1009-1014.

-32 Hallan SI, Orth SR: The Conundrum of chronic kidney disease classification and end stage renal risk prediction in the elderly- what is the right approach? Nephron Clin Pract 2010;116:c307-c316.

33 National Kidney Foundation- Kidney Disease Outcomes Quality Initiative: Clinical practice guidelines for chronic kidney disease- evaluation, classification, and stratification. Am J Kidney Dis 2002;39:s1-s246.

-34 Murata K, Baumann NA, Saenger AK, Larson TS, Rule AD, Lieske JC: Relative performance of the MDRD and CKD-EPI equations for estimating glomerular filtration rate among patients with varied clinical presentations. Clin J Am Soc Nephrol 2011;6:1963-1972.

35 James MT, Hemmelgarn BR, Tonelli M: Early recognition and prevention of chronic kidney disease. Lancet 2010;375:1296-1309.

36 De Nicola L, Minutolo R, Chiodini P, Zoccali C, Castellino P, Donadio C, Strippoli M, Casino F, Giannattasio M, Petrarulo F, Virgilio M, Laraia E, Di lorio BR, Savica V, Conte G; Target Blood Pressure Levels in Chronic Kidney Disease (TABLE in CKD) Study Group: Global approach to cardiovascular risk in chronic kidney disease: reality and opportunities for intervention. Kidney Int 2006;69:538-545.

-37 Hoefield RA, Kalra PA, Baker P, Lane B, New JP, O’Donoghue DJ, Foley RN, Middleton RJ: Factors Associated with kidney disease progression and mortality in a referred CKD population. Am J Kidney Dis 2010;56:1072-1081.

38 Obi Y, Kimura T, Nagasawa Y, Yamamoto R, Yasuda K, Sasaki K, Kitamura H, Imai E, Rakugi H, Isaka Y, Hayashi T: Impact of age and overt proteinuria on outcomes of stage 3 to 5 chronic kidney disease in a referred cohort. Clin J Am Soc Nephrol 2010;5:1558-1565.

-39 Winkelmayer WC, Liu J, Chertow GM, Tamura MK: Predialysis nephrology care of older patients approaching end-stage renal disease. Arch Intern Med 2011;171:1371-1378.

40 John R, Webb M, Young A, Stevens PE: Unreferred chronic kidney disease: a longitudinal study. Am J Kidney Dis 2004;43:825-835.

41 Patel UD, Young EW, Ojo AO, Hayward RA: CKD progression and mortality among older patients with diabetes. Am J Kidney Dis 2005;46:406-414.

42 Minutolo R, De Nicola L, Zamboli P, Chiodini P, Signoriello G, Toderico C, Arfe G, Boschi G, Brancati C, laccarino P, Conte G: Management of hypertension in patients with CKD: differences between primary and tertiary care settings. Am J Kidney Dis 2005;46:18-25.

43 Peralta CA, Shlipak MG, Fan D, Ordonez J, Lash JP, Chertow GM, Go AS: Risks for end-stage renal disease, cardiovascular events, and death in Hispanic vs. non-Hispanic white adults with chronic kidney disease. J Am Soc Nephrol 2006;17:2892-2899.

44 Muntner P, Bowling CB, Gao L, Rizk D, Judd S, Tanner RM, McClellan W, Warnock DG: Age-specific association of reduced estimated glomerular filtration rate and albuminuria with all-cause mortality. Clin J Am Soc Nephrol 2011;6:2200-2207.

-45 Hemmelgarn BR, Zhang J, Manns BJ, Tonelli M, Larsen E, Ghali WA, Southern DA, McLaughlin K, Mortis G, Culleton BF: Progression of kidney dysfunction in the community-dwelling elderly. Kidney Int 2006;69:2155-2161.

-46 O'Hare AM, Choi AI, Bertenthal D, Bacchetti P, Garg AX, , Kaufman JS, Walter LC, Mehta KM, Steinman MA, Allon M, McClellan WM, Landefeld CS: Age affects outcomes in chronic kidney disease. J Am Soc Nephrol 2007;18:2758-2765.

47 Hsu CY, Iribarren C, McCulloch CE, Darbinian J, Go AS: Risk factors for end-stage renal disease: 25-year follow-up. Arch Intern Med 2009;169:342-350.

48 De Nicola L, Minutolo R, Chiodini P, Borrelli S, Zoccali C, Postorino M, Iodice C, Nappi F, Fuiano G, Gallo C, Conte G; Italian Society of Nephrology Study group Target Blood pressure Levels (TABLE) in CKD. The effect of increasing age on the prognosis of non-dialysis patients with chronic kidney disease receiving stable nephrology care. Kidney Int 2012;82:482-488. 


\section{Kidney \\ Blood Pressure Research}

Kidney Blood Press Res 2013;38:109-120

DOI: $10.1159 / 000355760$

Published onine: IVarch 03, 2014

(C) 2014 S. Karger AG, Basel

www.karger.com/kbr

Nitta/Okada/Yanai/Takahashi: Aging and CKD

-49 O’Hare AM, Hailpern SM, Pavkov ME, Rios-Burrows N, Gupta I, Maynard C, Todd-Stenberg J, Rodriguez RA, Hemmelgarn BR, Saran R, Williams DE: Prognostic implications of the urinary albumin to creatinine ratio in veterans of different ages with diabetes. Arch Intern Med 2010;170:930-936.

50 Go AS, Chertow GM, Fan D, McCulloch CE, Hsuy CY: Chronic kidney disease and the risks of death, cardiovascular events and hospitalization. N Eng J Med 2004;351:1296-1305.

-51 El Nahas AM, Bello AK: Chronic kidney disease: the global challenge. Lancet 2005;365:331-341.

-52 O’Hare AM, Berthental D, Covinsky KE, Landefeld CS, Sen S, Mehta K, Steinman MA, Borzecki A, Walter LC: Mortality risk stratification in chronic kidney disease: one size for all ages? J Am Soc Nephrol 2006;17:846853.

53 Roderick PJ, Atkins RJ, Smeeth L, Mylne A, Nitsch DD, Hubbard RB, Bulpitt CJ, Fletcher AE: CKD and mortality risk in older people: a community-based population study in the United Kingdom. Am J Kidney Dis 2009;53:950-960.

54 Buemi M, Lacquaniti A, Bolignano D, Donato V, Fazio MR, Campo S, Coppolino G, Sturiale A: Dialysis and the elderly: An underestimated problem. Kidney Blood Press Res 2008;31:330-336.

55 Kurella Tamura M: Incidence, management, and outcomes of end-stage renal disease in the elderly. Curr Opin Nephrol Hypertens 2009;18:252-257.

-56 Cooper BA, Branley P, Bulfone L, Collins JF, Craig JC, Fraenkel MB,HarrisA, JohnsonDW, Kesselhut J, Li JJ, LuxtonG, PilmoreA, Tiller DJ, Harris DC, Pollock CA; IDEAL Study: A randomized, controlled trial of early versus late initiation of dialysis. N Engl J Med 2010;363:609-619.

-57 Rosansky SJ, Eggers P, Jackson K, Glassock RJ, Clark WF: Early start of hemodialysis may be harmful. Arch Intern Med 2011;171:396-403.

58 Renal Physicians Association: Shared decision-making in the appropriate initiation of and withdrawal from dialysis, 2nd Ed., Rockville, MD, Renal Physicians Association, 2010.

59 Germain MJ, Davison SN, Moss AH: When enough is enough: the nephrologist's responsibility in ordering dialysis treatments. Am J Kidney Dis 2011;58:135-143.

60 Quill TE, Holloway R: Time-limited trials near the end of life. JAMA 2011;306:1483-1484.

61 Burns A, Davenport A: Maximum conservative management for patients with chronic kidney disease stage 5. Hemodial Int 2010;14:S32-S37.

62 Busuioc M, Gusbeth-Tatomir P, Covic A: Dialysis or not in the very elderly ESRD patient. Int Urol Nephrol 2008;40:1127-1132.

63 De Biase V, Tobaldini O, Boaretti C, Abaterusso C, Pertica N, Loschiavo C, Trabucco G, Lupo A, Gambaro G: Prolonged conservative treatment for frail elderly patients with end-stage renal disease: the Verona experience. Nephrol Dial Transplant 2008;23:1313-1317.

64 Visser A, Dijkstra GJ, Kuiper D, de Jong PE, Franssen CFM, Gansevoort RT, Izaks GJ, Jager KJ, Reijneveld SA: Accepting or declining dialysis: considerations taken into account by elderly patients with end-stage renal disease. J Nephrol 2009;22:794-799.

65 Murtagh FEM, Marsh JE, Donohoe P, Ekbal NJ, Sheerin NS, Harris FE: Dialysis or not? A comparative survival study of patients over 75 years with chronic kidney disease stage 5. Nephrol Dial Transplant 2007;22:1955-1962.

66 Smith C, Da Silva-GaneM, Chandna S,Warwicker P, Greenwood R, Farrington K: Choosing not to dialyse: evaluation of planned non-dialytic management in a cohort of patients with end-stage renal failure. Nephron Clin Pract 2003;95:c40-c46.

67 Carson RC, Juszczak M, Davenport A, Burns A: Is maximum conservative management an equivalent treatment option to dialysis for elderly patients with significant comorbid disease? Clin J Am Soc Nephrol 2009;4:1611-1619.

68 Choudhury D, Levi M: Kidney aging-inevitable or preventable? Nat Rev Nephrol 2011;7:706-717.

69 Kanasaki K, Kitada M, Koya D: Pathophysiology of the aging kidney and therapeutic interventions. Hypertens Res 2012;35:1121-1128.

70 Lin SJ, Defossez PA, Guarente L: Requirement of NAD and SIR2 for life-span extension by calorie restriction in Saccharomyces cerevisiae. Science 2000;289:2126-2128.

71 Colman RJ, Anderson RM, Johnson SC, Kastman EK, Kosmatka KJ, Beasley TM, Allison DB, Cruzen C, Simmons HA, Kemnitz JW, Weindruch R: Caloric restriction delays disease onset and mortality in rhesus monkeys. Science 2009;325:201-204. 


\section{Kidney \\ Blood Pressure Research}

Kidney Blood Press Res 2013;38:109-120

DOI: $10.1159 / 000355760$

Publisned onIIne: VIarch 03, 2014

(C) 2014 S. Karger AG, Basel

Nitta/Okada/Yanai/Takahashi: Aging and CKD

72 Liang F, Kume S, Koya D: SIRT1 and insulin resistance. Nat Rev Endocrinol 2009;5:367-373.

-73 Cohen HY, Miller C, Bitterman KJ, Wall NR, Hekking B, Kessler B, Howitz KT, Gorospe M, de Cabo R, Sinclair DA: Calorie restriction promotes mammalian cell survival by inducing the SIRT1 deacetylase. Science 2004;305:390-392.

74 Kume S, Uzu T, Horiike K, Chin-Kanasaki M, Isshiki K, Araki S, Sugimoto T, Haneda M, Kashiwagi A, Koya D: Calorie restriction enhances cell adaptation to hypoxia through Sirt1-dependent mitochondrial autophagy in mouse aged kidney. J Clin Invest 2010;120:1043-1055.

75 Bordone L, Cohen D, Robinson A, Motta MC, van Veen E, Czopik A, Steele AD, Crowe H, Marmor S, Luo J, Gu W, Guarente L: SIRT1 Transgenic mice show phenotypes resembling calorie restriction. Aging Cell 2007;6:759-767.

-76 Sharma S, Anjaneyulu M, Kulkarni SK, Chopra K: Resveratrol a polyphenolic phytoalexin, attenuates diabetic nephropathy in rats. Pharmacology 2006;76:69-75.

77 Tikoo K, Singh K, Kabra D, Sharma V, Gaikwad A: Change in histone H3 phosphorylation, MAP kinase p38, SIR 2 and p53 expression by resveratrol in preventing streptozotocin induced type I diabetic nephropathy. Free Radic Res 2008;42:397-404.

78 Ding DF, You N, Wu XM, Xu JR, Hu AP, Ye XL, Zhu Q, Jiang XQ Miao H, Liu C, Lu YB: Resveratrol attenuates renal hypertrophy in early-stage diabetes by activating AMPK. Am J Nephrol 2010;31:363-374.

79 Kitada M, Kume S, Imaizumi N, Koya D: Resveratrol improves oxidative stress and protects against diabetic nephropathy through normalization of Mn-SOD dysfunction in AMPK/SIRT1-independent pathway. Diabetes 2011;60:634-643.

-80 Kuro-o M, Matsumura Y, Aizawa H, Kawaguchi H, Suga T, Utsugi T, Ohyama Y, Kurabayashi M, Kaname T, Kume E, Iwasaki H, Iida A, Shiraki-Iida T, Nishikawa S, Nagai R, Nabeshima YI: Mutation of the mouse Klotho gene leads to a syndrome resembling aging. Nature 1997;390:45-51.

-81 Kurosu H, Yamamoto M, Clark JD, Pastor JV, Nandi A, Gurnani P, McGuinness OP, Chikuda H, Yamaguchi M, Kawaguchi H, Shimomura I, Takayama Y, Herz J, Kahn CR, Rosenblatt KP, Kuro-o M: Suppression of aging in mice by the hormone Klotho. Science 2005;309:1829-1833.

-82 Kuro-o M: Klotho and the aging process. Korean J Intern Med 2011;26:113-122.

83 Kuro-o M: A potential link between phosphate and aging-lessons from Klotho-deficient mice. Mech Aging Dev 2010;131:270-275.

84 Stenvinkel P: Chronic kidney disease: a public health priority and harbinger of premature cardiovascular disease. J Intern Med 2010;268:456-467.

85 Kuro OM: Klotho in health and disease. Curr Opin Nephrol Hypertens 2012;21:362-368.

-86 Wolf M: Update on fibroblast growth factor 23 in chronic kidney disease. Kidney Int 2012;82:737-747. 